\title{
Importance of Lutzomyia longipalpis in the dynamics of transmission of canine visceral leishmaniasis in the endemic area of Porteirinha Municipality, Minas Gerais, Brazil ${ }^{\text {光 }}$
}

\author{
João C. França-Silva ${ }^{a, *}$, Ricardo A. Barata ${ }^{b}$, Roberto T. da Costa ${ }^{a}$, \\ Érika Michalsky Monteiro ${ }^{b}$, George L. L. Machado-Coelho ${ }^{c}$, \\ Edvá P. Vieira ${ }^{\mathrm{d}}$, Aluisio Prata ${ }^{\mathrm{e}}$, Wilson Mayrink ${ }^{\mathrm{a}}$, Evaldo Nascimento ${ }^{\mathrm{a}}$, \\ Consuelo L. Fortes-Dias ${ }^{\mathrm{f}}$, Jaime C. da Silva ${ }^{\mathrm{d}}$, Edelberto S. Dias ${ }^{\mathrm{b}}$ \\ ${ }^{a}$ Departamento de Parasitologia, Universidade Federal de Minas Gerais, Av. Antônio Carlos 6627, \\ CEP 31270-901, Belo Horizonte, MG, Brazil \\ ${ }^{\mathrm{b}}$ Centro de Pesquisas René Rachou/Fiocruz, Belo Horizonte, MG, Brazil \\ ${ }^{\mathrm{c}}$ Faculdade de Farmácia, Universidade Federal de Ouro Preto, MG, Brazil \\ ${ }^{\mathrm{d}}$ Secretaria de Vigilância da Saúde, Ministério da Saúde, MG, Brazil \\ ${ }^{\mathrm{e}}$ Faculdade de Medicina do Triângulo Mineiro, Uberaba, MG, Brazil \\ ${ }^{\mathrm{f}}$ Fundação Ezequiel Dias, Belo Horizonte, MG, Brazil
}

Received 7 October 2004; received in revised form 1 May 2005; accepted 3 May 2005

\begin{abstract}
A study of Lutzomyia longipalpis (Lutz and Neiva, 1912) (Diptera: Psychodidae), the primary vector of American visceral leishmaniasis (AVL), and the canine form of the disease, was carried out in Porteirinha. The city is situated in the northern part of the Brazilian State of Minas Gerais and is an endemic area of AVL. Systematic phlebotomine captures were performed in seven districts with previously reported cases of canine visceral leishmaniasis, during 2 years (January 2000December 2001). A total of 2328 specimens of L. longipalpis were captured. The association between the local climate variables and the population density of L. longipalpis was evaluated and rainfall was determined to be a major factor, with increased populations during the rainy season (October-March). At the same time period, blood samples from every dog domiciled in the same seven districts, in total 14,077 animals, were analyzed for infection by viscerotropic Leishmania using indirect immunofluorescence assay (IFA). Accumulated incidence rates of canine VL per district varied from 3.40 to 14.34
\end{abstract}

\footnotetext{
This work is part of the Doctoral Thesis of J.C. França-Silva.

* Corresponding author. Tel.: +55 313499 2859; fax: +55 3134992871.

E-mail address: franca@icb.ufmg.br (J.C. França-Silva).
} 
for the 2-year period. A positive correlation between the population density of $L$. longipalpis and the canine cases of visceral leishmaniasis in Porteirinha was observed.

(C) 2005 Elsevier B.V. All rights reserved.

Keywords: Canine visceral leishmaniasis; Leishmaniasis; Lutzomyia longipalpis; Phlebotomine; Porteirinha

\section{Introduction}

Leishmaniases are tropical diseases of great importance in human and veterinary medicine, caused by parasites from the order Kinetoplastida, genus Leishmania, Ross, 1903 (Protozoa: Trypanosomatidae). The transmission occurs mainly via the bites of infected females of certain species of phlebotomine sand flies. Lutzomyia longipalpis (Lutz and Neiva, 1912) (Diptera: Psychodidae: Phlebotominae) is the primary vector of the human and canine visceral leishmaniases (AVL) in the New World. More recently, Lutzomyia cruzi Mangabeira, 1938 and Lutzomyia evansi (Nunez-Tovar, 1924) have been incriminated as possible vectors in Brazil and Colombia, respectively (Travi et al., 1990, 1996; Galati et al., 1997; Santos et al., 1998). The causative agent of AVL is Leishmania (Leishmania) chagasi.

Until two decades ago, AVL was considered to be a rural disease. However, environmental modifications caused by man and the constant migration of rural populations to suburban areas led to the urbanization of the AVL (Deane and Deane, 1955; Marzochi and Marzochi, 1994; Bejarano et al., 2002). Today, what is observed in Brazil is the presence of AVL in both rural and urban areas. In the state of Minas Gerais, the urbanization phenomenon is substantiated by an increasing number of human and canine cases in medium and large size cities, such as Montes Claros (260,000 inhabitants) and Belo Horizonte $(2,300,000$ inhabitants) (Silva et al., 2001; França-Silva et al., 2003).

Basic aspects of the biology of phlebotomine are studied all over the world, most of them using laboratory reared specimens. Nevertheless, field studies requiring systematic captures for consecutive months are crucial to assist in the development of more efficient methods for the control of AVL (Grimaldi and Tesh, 1993). This fact motivated us to undertake a survey on the phlebotomine fauna and canine cases of visceral leishmaniasis in an endemic area, in an effort to understand some aspects of the dynamics of transmission of the disease in Brazil.

\section{Methodology}

\subsection{Geographical area under study}

Porteirinha $\left(15^{\circ} 44^{\prime} 42^{\prime \prime} \mathrm{S}, 43^{\circ} 01^{\prime} 46^{\prime \prime} \mathrm{W}\right)$ is located in the northern region of the state of Minas Gerais, $592 \mathrm{~km}$ distant from the state's capital. The municipality occupies an area of $1788 \mathrm{~km}^{2}$ with an average altitude of $567 \mathrm{~m}$, within the named "dry-land polygon". The local population of Porteirinha consists of 35,465 inhabitants, from which $41 \%$ are in the urban area. The climate is tropical semi-humid, with an average temperature of $24{ }^{\circ} \mathrm{C}$ and a dry season of about 6 months per year. The city of Porteirinha comprises 12 districts distributed on hills (higher region) and in the wide valleys (lower region).

\subsection{Phlebotomine captures}

Phlebotomine captures were performed in seven districts of the city of Porteirinha (Fig. 1). Three of these districts (São Judas, Vila Vitória and Vila União) are situated in the higher region of Porteirinha. The other four districts (Vila Serranópolis, Vila Kennedy, Renascença and São Sebastião) are located in the wide valleys. Two fixed capture sites were scheduled per district, where there had been cases of canine visceral leishmaniasis in the semester immediately before the beginning of the present study. Two CDC light traps (Sudia and Chamberlain, 1962) were used per site, one inside a house (preferentially in the bedroom) and the other in its surroundings (in orchards, nearby housing of domestic animals). Twenty-eight traps were used in total. The sand flies were captured at night with traps assembled at 18:00 $\mathrm{h}$ and taken down at 08:00 $\mathrm{h}$ the next day, for 5 consecutive days in the last week of each month, from January 2000 to December 2001. 


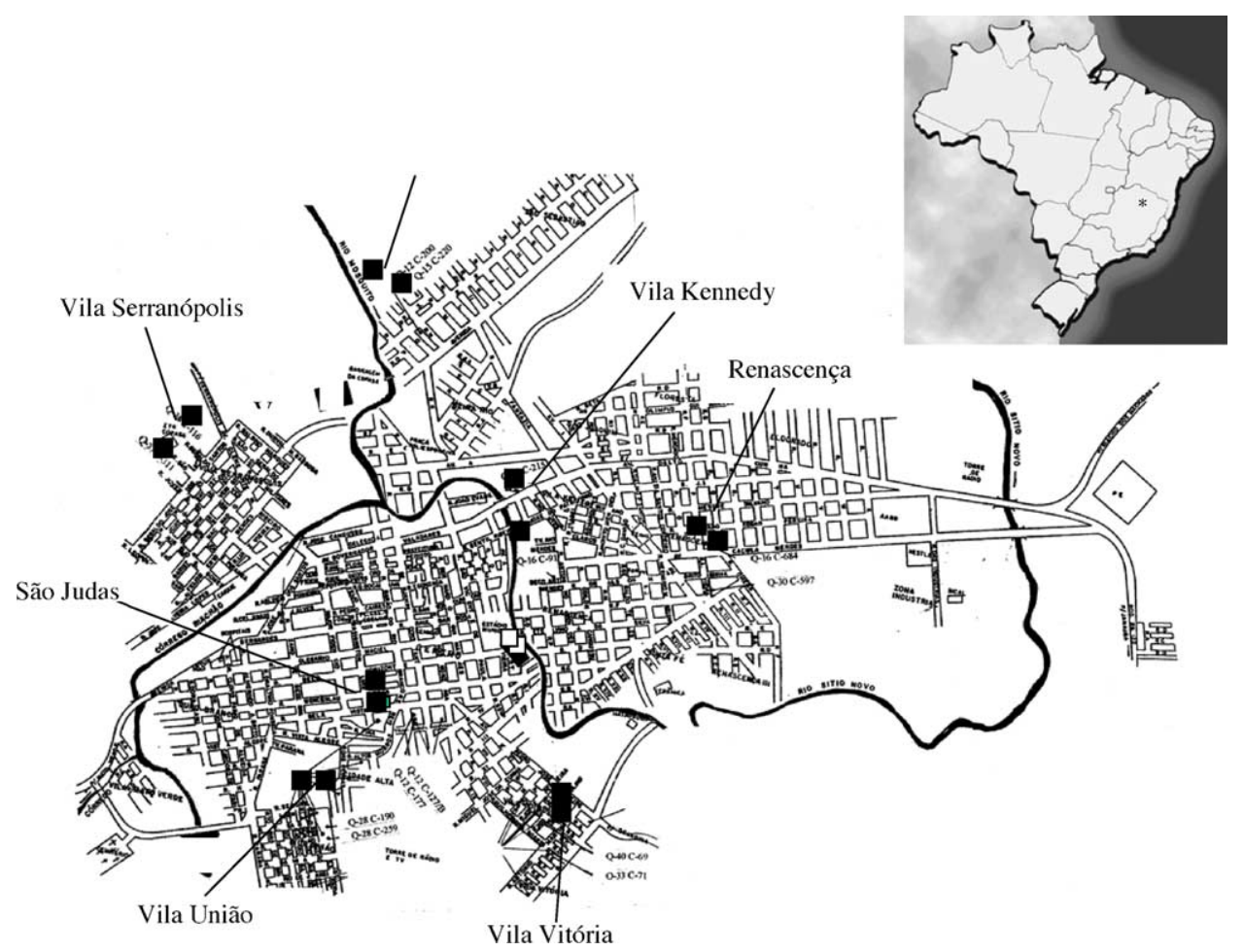

Fig. 1. Geographical localization (*) and map of the urban area of Porteirinha in the state of Minas Gerais (Brazil). The fixed sites of phlebotomine sand fly captures are indicated by black squares.

The specimens were preserved in glass vials containing $70 \%$ ethanol and then mounted on microscope slides. Canada balsam and Berlese medium were used for the treatment of males and females, respectively. Taxonomic identification was performed according to Young and Duncan (1994).

The monthly sand fly data were compiled in trimesters in order to allow comparison with the canine population survey. During the period of our study, there was no application of insecticide by the local public health service.

\subsection{Canine population survey}

The 2-year period (January 2000-December 2001) of study was divided into quarters. In the first days of each trimester, blood samples from every dog domiciled in Porteirinha were collected on filter paper (Klabin no. 25) by França-Silva. Identification data of each dog were recorded. The blood samples were brought to our laboratory at the Universidade Federal de Minas Gerais for analysis by indirect immunofluorescence assay (IFA), as described by Camargo and Rebonato (1969). Briefly, promastigote forms from Leishmania (Leishmania) mexicana (strain MHOM/BR/60/BH6) in exponential phase of growth in liver infusion trypticase (LIT) medium were used as antigen. Two $6 \mathrm{~mm}$ confettis were punched from the filter paper impregnated with the dog's blood and eluted with $0.28 \mathrm{ml}$ of PBS under shaking for $1 \mathrm{~h}$. Anti-dog IgG-FITC conjugate antibody produced in rabbit (BioManguinhos, FIOCRUZ, Rio de Janeiro, Brazil) was added to increasing dilutions of the sample eluates. The cut off discriminative titer of 1:40 was used according to Costa et al. (1991). Positive tests were repeated twice with new blood samples.

Every trimester, the positive dogs were confiscated and eliminated in the Center for Zoonoses Control, Montes Claros, MG. The positive cases in the following trimester were considered as new cases.

The incidence rates of canine visceral leishmaniasis were calculated as the number of new positive 
cases divided by the number of dogs examined and multiplied by 1000 .

\subsection{Statistical analysis}

Daily rainfall, temperature and relative humidity data were provided by the climatological station of the Empresa de Pesquisas Agropecuárias de Minas Gerais (EPAMIG), a government research center devoted to agriculture, that monitors the weather in the region of study. To allow comparison with the canine population survey, average values for the climate variables were calculated per trimester and used as such. Any possible association between those climate variables and the population of phlebotomine sand flies was first tested by the linear best subsets regression method. In this case, the coefficient of determination $R^{2}$ was used as a measure of how well the regression model described the data for the variables being tested. The Pearson Product Moment Correlation method was also employed to investigate any possible association between the population of phlebotomine sand flies and the number of canine cases of visceral leishmaniasis. The Sigma Stat software (Jandel, 1995) was used for all statistical analysis.

\section{Results}

A total of 3240 phebotomine sand flies were collected during 2 years of study in Porteirinha. Of them, 2328 specimens were L. longipalpis $(71.85 \%)$ with $1683(72.3 \%)$ male insects and $645(27.7 \%)$ female specimens. A detailed description of the local phlebotomine fauna has been published previously (Barata et al., 2004).

During the experimental period, the weather in the region was monitored and three main climate variables were measured (Table 1). The contribution of each of them to the prediction of the number of L. longipalpis captured was tested by best subsets regression. Three mathematical models were computer generated, taking into account one, two or three of these variables at a time. A significant association between the independent variable 'rainfall' and the dependent variable ' $L$. longipalpis' was found with $R^{2}$ equal to 0.982 with $P$ value $<0.001$. The inclusion of the two other variables (relative humidity and temperature) in the model did not significantly add to the prediction of 'L. longipalpis'. Then, further analysis of the effect of the bioclimate on the number of $L$. longipalpis captured was performed based solely on the rainfall.

Two seasons were clearly defined in Porteirinha, that is, a rainy season (October-March) and a dry season (April-September) (Fig. 2). The populational density of L. longipalpis and the rainfall followed a similar curve profile (Fig. 2). Undoubtedly, the number of $L$. longipalpis captured increased during the rainy season.

The distribution of $L$. longipalpis per district of Porteirinha is illustrated in Fig. 3. The highest numbers of this phlebotomine sand fly were collected in São Judas (953) and Vila União (567) whereas a minimum (22) was collected in Vila Kennedy (Fig. 3).

During the same 2-year period, blood samples from 14,077 dogs domiciled in Porteirinha were collected and analyzed for the presence of Leishmania. The number of IFA reactions totalled 21,082, including repetitions and confirmatory reactions. Table 2 sum-

Table 1

Climate data in Porteirinha, state of Minas Gerais (Brazil), from January 2000 to December $2001^{\text {a }}$

\begin{tabular}{lllr}
\hline Quarter/year & Temperature $\left({ }^{\circ} \mathrm{C}\right)$ & Relative humidity $(\%)$ & Rainfall $(\mathrm{mm})$ \\
\hline January-March/2000 & 25.7 & 67.9 & 152.0 \\
April-June/2000 & 24.2 & 52.6 & 0.1 \\
July-September/2000 & 23.9 & 46.9 & 3.7 \\
October-December/2000 & 26.3 & 60.5 & 143.7 \\
January-March/2001 & 26.4 & 59.4 & 65.6 \\
April-June/2001 & 25.3 & 52.5 & 8.1 \\
July-September/2001 & 24.4 & 45.9 & 1.4 \\
October-December/2001 & 26.1 & 62.2 & 185 \\
\hline
\end{tabular}

Data are expressed as the arithmetic mean of daily values.

${ }^{a}$ Daily values provided by the climatological station of the Empresa de Pesquisas Agropecuárias de Minas Gerais (EPAMIG). 


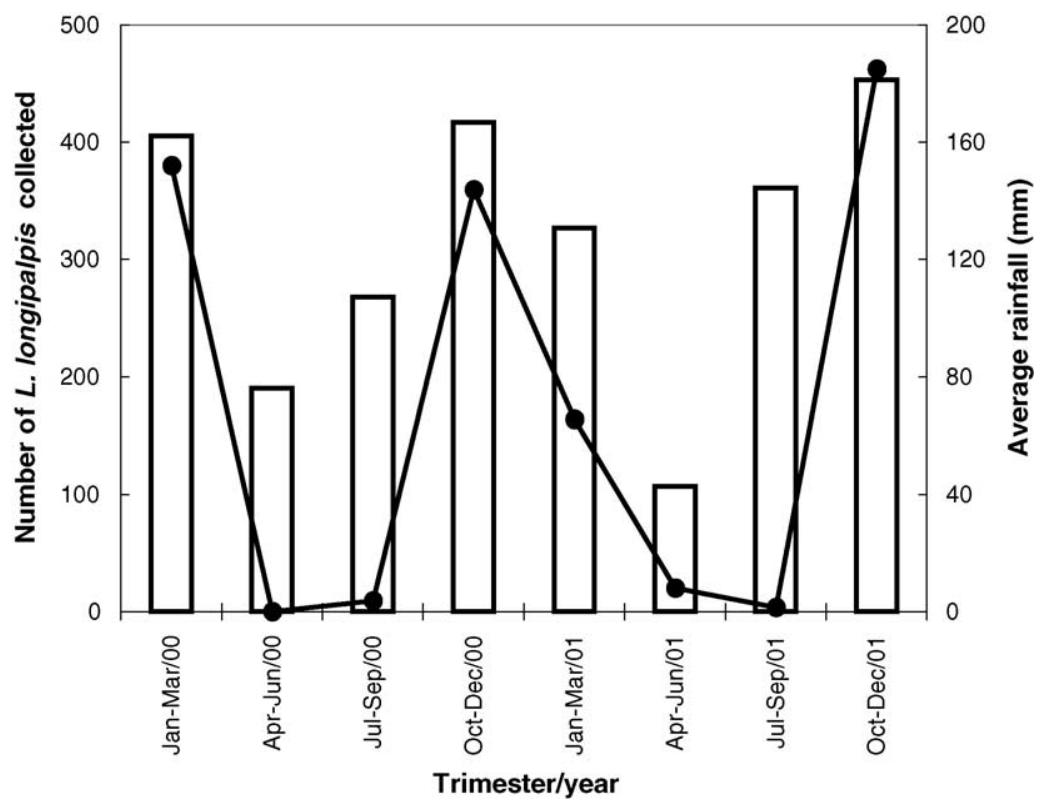

Fig. 2. Average rainfall (line) and number of Lutzomyia longipalpis (bar) captured in Porteirinha (Brazil) per trimester, from January 2000 to December 2001.

marizes the results obtained. The incidence rates of canine visceral leishmaniasis varied within the range $0-50.36$, depending on the district and on the trimester analyzed. Accumulated 2-year incidence rates between 3.40 and 14.34 were found in Vila Serranópolis and Renascença, respectively. In the first trimester of 2000, the accumulated incidence rates for all districts was the highest of the whole period,

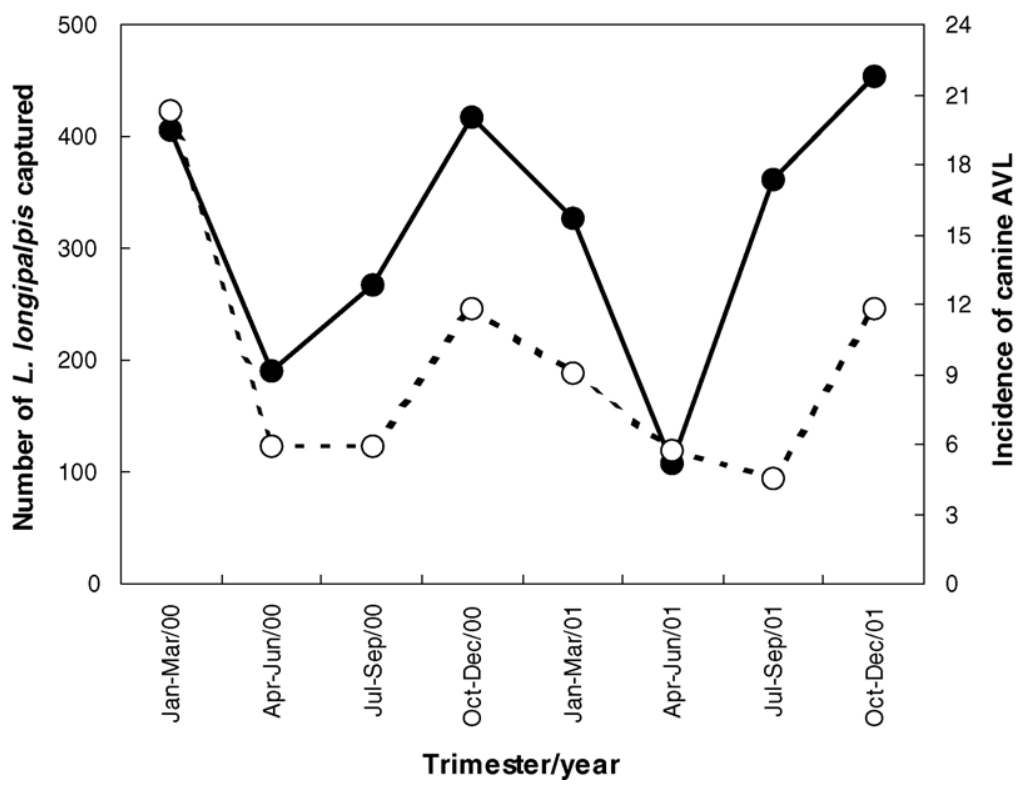

Fig. 3. Incidence of canine visceral leishmaniasis (o) and number of Lutzomyia longipalpis captured (•) per quarter of year (January 2000December 2001) in Porteirinha, state of Minas Gerais (Brazil). 
Table 2

New cases and incidence rates of canine visceral leishmaniasis per quarter of year and per district of Porteirinha, state of Minas Gerais, Brazil, between January 2000 and December 2001

\begin{tabular}{|c|c|c|c|c|c|c|c|c|c|}
\hline \multirow[t]{2}{*}{ Quarter/year } & \multirow{2}{*}{$\begin{array}{l}\text { Number of } \\
\text { dogs or rate }\end{array}$} & \multicolumn{8}{|l|}{ District } \\
\hline & & Renascença & $\begin{array}{l}\text { S. Judas } \\
\text { Tadeu }\end{array}$ & $\begin{array}{l}\text { São } \\
\text { Sebastião }\end{array}$ & $\begin{array}{l}\text { Vila } \\
\text { Kennedy }\end{array}$ & $\begin{array}{l}\text { V. } \\
\text { Serranópolis }\end{array}$ & $\begin{array}{l}\text { Vila } \\
\text { União }\end{array}$ & $\begin{array}{l}\text { Vila } \\
\text { Vitória }\end{array}$ & All \\
\hline \multirow[t]{2}{*}{ January-March/2000 } & Positive/examined & $5 / 148$ & $3 / 292$ & $3 / 126$ & $2 / 205$ & $2 / 176$ & 7/139 & $3 / 144$ & $25 / 1230$ \\
\hline & Incidence & 33.78 & 10.27 & 23.81 & 9.76 & 11.36 & 50.36 & 20.83 & 20.32 \\
\hline \multirow[t]{2}{*}{ April-June/2000 } & Positive/examined & $1 / 167$ & $2 / 318$ & $1 / 137$ & $2 / 215$ & $0 / 200$ & $2 / 152$ & $0 / 172$ & $8 / 1361$ \\
\hline & Incidence & 5.99 & 6.29 & 7.30 & 9.30 & 0 & 13.16 & 0 & 5.88 \\
\hline \multirow[t]{2}{*}{ July-September/2000 } & Positive/examined & $0 / 184$ & $3 / 354$ & $2 / 162$ & $2 / 234$ & $0 / 223$ & $1 / 171$ & $1 / 195$ & $9 / 1523$ \\
\hline & Incidence & 0 & 8.47 & 12.35 & 5.85 & 0 & 5.85 & 5.13 & 5.91 \\
\hline \multirow[t]{2}{*}{ October-December/2000 } & Positive/examined & $5 / 203$ & $4 / 378$ & $1 / 169$ & $4 / 274$ & $1 / 244$ & $4 / 212$ & $1 / 211$ & 20/1691 \\
\hline & Incidence & 24.63 & 10.58 & 5.91 & 14.60 & 4.10 & 18.87 & 4.74 & 11.83 \\
\hline \multirow[t]{2}{*}{ January-March/2001 } & Positive/examined & $4 / 219$ & $3 / 420$ & $2 / 190$ & $3 / 307$ & $0 / 269$ & $2 / 235$ & $3 / 236$ & $17 / 1876$ \\
\hline & Incidence & 18.26 & 7.14 & 10.53 & 9.77 & 0 & 8.51 & 12.71 & 9.06 \\
\hline \multirow[t]{2}{*}{ April-June/2001 } & Positive/examined & $1 / 230$ & $6 / 456$ & $2 / 219$ & $0 / 220$ & $2 / 298$ & $0 / 246$ & $0 / 245$ & $11 / 1914$ \\
\hline & Incidence & 4.35 & 13.16 & 9.13 & 0 & 6.71 & 0 & 0 & 5.75 \\
\hline \multirow[t]{2}{*}{ July-September/2001 } & Positive/examined & $2 / 258$ & $4 / 516$ & $0 / 226$ & $2 / 369$ & $1 / 316$ & $1 / 255$ & $0 / 263$ & $10 / 2203$ \\
\hline & Incidence & 7.75 & 7.75 & 0 & 5.42 & 3.16 & 3.92 & 0 & 4.54 \\
\hline \multirow[t]{2}{*}{ October-December/2001 } & Positive/examined & $6 / 265$ & $8 / 525$ & $2 / 240$ & $4 / 382$ & $1 / 333$ & $4 / 261$ & $2 / 273$ & $27 / 2279$ \\
\hline & Incidence & 22.64 & 15.24 & 8.33 & 10.47 & 3.00 & 15.33 & 7.33 & 11.85 \\
\hline \multirow[t]{2}{*}{ Whole period } & Positive/examined & $24 / 1674$ & $33 / 3259$ & $13 / 1469$ & $19 / 2206$ & $7 / 2059$ & $21 / 1671$ & $10 / 1739$ & $127 / 14077$ \\
\hline & Incidence & 14.34 & 10.13 & 8.85 & 8.61 & 3.40 & 12.57 & 5.75 & 9.02 \\
\hline
\end{tabular}

reaching 20.32 (Fig. 3). The populational fluctuation of $L$. longipalpis and the incidence rates per quarter of year (Fig. 3) followed a similar curve pattern, suggesting a correlation between these variables during the time period.

A possible association was indicated when the population of $L$. longipalpis and the number of new positive dog cases were plotted per district (Fig. 4). A statistical analysis by the Pearson Product Moment Correlation method confirmed a positive correlation between the two variables. A correlation coefficient of 0.823 was found with $P=0.0123(P<0.05)$, indicating that the two variables tend to increase together.

\section{Discussion}

L. longipalpis is present in a variety of habitats, from dry and rocky to humid areas such as the Amazon basin (Young and Duncan, 1994). However, a discontinuity in its geographical distribution and contradictory observations on host preference as well as on endophagic behavior have been considered as indicative of a process of speciation (Deane and Deane, 1962; Sherlock and Guitton, 1969; Quinell and Dye, 1994a,b; Tesh, 1995). Experimental laboratory crossing of sympatric populations have pointed toward a complex of species, more recently corroborated by genetic studies (Ward et al., 1983; Lanzaro et al., 1993; Dias et al., 1998). Nevertheless, further studies with field-caught instead of laboratory reared specimens are still needed to definitely solve the number and punctual geographical distribution of subspecies of L. longipalpis (Tesh, 1995).

Independently of its taxonomic status or geographical distribution, a common characteristic of $L$. longipalpis is its capability to adapt to the peridomestic environment, particularly in rural or suburban areas with an abundance of domestic animals and animal shelters (Lainson, 1989). In the urban region of Porteirinha, L. longipalpis is present in high numbers. In fact, it was shown to be the predominant species 


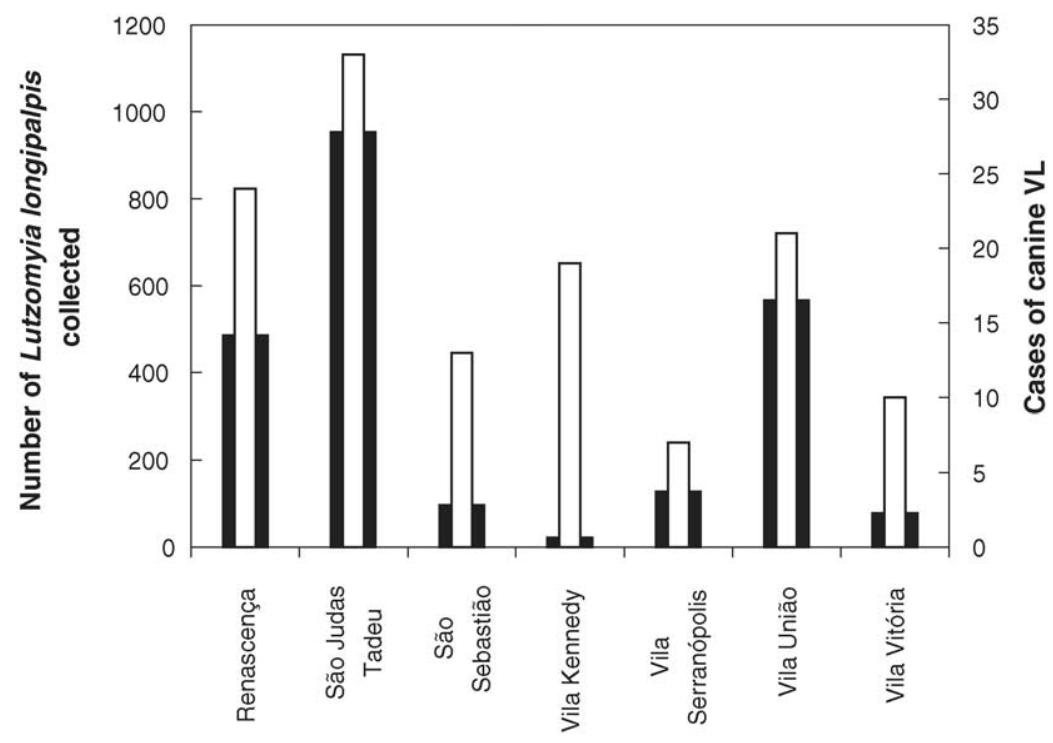

District of Porteirinha

Fig. 4. Distribution of Lutzomyia longipalpis population (black bars) and new cases of canine AVL (white bars) per district of Porteirinha, between January 2000 and December 2001. A significant association between the two variables was found by Pearson product moment correlation analysis, with a correlation coefficient $(r)$ of 0.823 and $P=0.0123(P<0.05)$.

(71.85\%) in a concomitant survey of the phlebotomine sand flies fauna in that city (Barata et al., 2004). The observed increase of the population of $L$. longipalpis in the rainy season in this study is in accordance with the findings of Marzochi and Marzochi (1994). These authors also observed a peak of VL transmission in that season, when the insects enter the domiciles at night to feed on humans and dogs. According to Deane and Deane (1955), the rain has another indirect additional effect in dry areas by favoring the growth of fresh vegetation for adequate sheltering and breeding of the phlebotomine.

The seasonal fluctuation of L. longipalpis is of major importance in the transmission of AVL. In Porteirinha, the transmission of such a disease followed the same pattern already described in the literature for other warm and dry regions (Deane and Deane, 1955; Marzochi and Marzochi, 1994; Sherlock, 1996). As the rate of Leishmania infection in the vector is usually low in nature, even in endemic areas of visceral leishmaniasis, a high density of phlebotomine seems crucial to increase the risk of transmission (Deane and Deane, 1955; Sherlock and Miranda, 1992).
The present study clearly demonstrates a positive correlation between the populational density of $L$. longipalpis and the canine visceral leishmaniasis in Porteirinha. As the population of $L$. longipalpis increases during the rainy season (October-March), so does the risk of transmission of the disease. These findings demonstrate that special attention must be devoted to this period by the Public Health Agencies for the control of AVL in Porteirinha.

\section{Acknowledgments}

The authors thank M.F. Rocha, W.G. Braga, J.F. Lima (Center for Zoonoses Control, Montes Claros) and J.V. Santos, S.N. Almeida, R.V. Almeida (FUNASA) for technical help in the field trips and collection of dog's blood. To people from Porteirinha for their collaboration during our study. This work was granted by Secretaria de Vigilância da Saúde do Ministério da Saúde, Universidade Federal de Minas Gerais (UFMG), Centro de Pesquisas René Rachou (CPqRR/FIOCRUZ) and Faculdade de Medicina do Triângulo Mineiro (FMTM). 


\section{References}

Barata, R.A., França-Silva, J.C., Costa, R.T., Fortes-Dias, C.L., Silva, J.C., Paula, E.V., Prata, A., Monteiro, E.M., Dias, E.S., 2004. Phlebotomine sand flies in Porteirinha, an area of American visceral leishmaniasis transmission in the state of Minas Gerais. Braz. Mem. Inst. Oswaldo Cruz 99, 481-487.

Bejarano, E.E., Uribe, S., Rojas, W., Vélez, I.D., 2002. Phlebotomine sand flies (Diptera: Psychodidae) associated with the appearance of urban leishmaniasis in the city of Sincelejo. Colombia Mem. Inst. Oswaldo Cruz 97, 645-647.

Camargo, M.E., Rebonato, C., 1969. Cross reactivity in fluorescent tests for Trypanosome and Leishmania antibodies. Am. J. Trop. Med. Hyg. 18, 500-505.

Costa, C.A., Genaro, O., De Lana, M., Magalhães, P.A., Dias, M., Michalick, M.S., Melo, N.M., da Costa, R.T., Magalhães-Rocha, N.M., Mayrinck, W., 1991. Leishmaniose visceral canina: avaliação da metodologia sorológica utilizada em inquéritos epidemiológicos. Rev. Soc. Bras. Med. Trop. 24, 21-25.

Deane, L.M., Deane, M.P., 1955. Leishmaniose visceral urbana (no cão e no homem) em Sobral. Ceará. O Hosp. 47, 75-87.

Deane, L.M., Deane, M.P., 1962. Visceral leishmaniasis in Brazil. Geographic distribution and transmission. Rev. Inst. Med. Trop. São Paulo 4, 149-212.

Dias, E.S., Fortes-Dias, C.L., Stiteler, J.M., Perkins, P.V., Lawyer, P.G., 1998. Random amplified polymorphic DNA (RAPD) analysis of Lutzomyia longipalpis laboratory populations. Rev. Inst. Med. Trop. São Paulo 40, 49-53.

França-Silva, J.C., Costa, R.T., Siqueira, A.M., Machado-Coelho, G.L.L., Costa, C.A., Mayrink, W., Vieira, E.P., Costa, J.S., Genaro, O., Nascimento, E., 2003. Epidemiology of canine visceral leishmanioses in the endemic area of Montes Claros Municipality, Minas Gerais State, Brazil. Vet. Parasitol. 111, 161-173.

Galati, E.A.B., Nunes, V.L.B., Rego Jr., F.A., Oshiro, E.T., Chang, M.R., 1997. Estudo de flebotomíneos (Diptera: Psychodidae) em foco de leishmaniose visceral no Estado de Mato Grosso do Sul. Bras. Rev. Saúde Pública 31, 378-390.

Grimaldi Jr., G., Tesh, R.B., 1993. Leishmaniasis of the New World: current concepts and implications for future research. Clin. Microbiol. 6, 230-250.

Jandel, 1995. Sigma Stat Statistical User's Manual, Version 2.0. Jandel, San Rafael, CA.

Lainson, R., 1989. Demographic changes and their influence on the epidemiology of the American leishmaniasis. In: Service, M.V. (Ed.), Demography and Vector-Borne Diseases. CRC, Boca Raton, pp. 85-106.

Lanzaro, G.C., Herrero, O.M.V., Lawyer, P.G., Warburg, A., 1993. Lutzomyia longipalpis is a species complex: genetic divergence and interspecific hybrid sterility among three populations. Am. J. Trop. Med. Hyg. 48, 839-847.

Marzochi, M.C.A., Marzochi, K.B.F., 1994. Tegumentary and visceral leishmaniases in Brazil—emerging anthropozoonosis and possibilities for their control. Cad. Saúde Pública 10, 359-375.

Quinell, R.J., Dye, C., 1994a. Correlates of the peridomestic abundance of Lutzomyia longipalpis (Diptera: Psychodidae) in Amazonian Brazil. Med. Vet. Entomol. 8, 219-224.

Quinell, R.J., Dye, C., 1994b. An experimental study of peridomestic distribution of Lutzomyia longipalpis (Diptera: Psychodidae). Bull. Entomol. Res. 84, 379-382.

Santos, S.O., Arias, J., Ribeiro, A.A., Hoffmann, M.P., Freitas, R.A., Malacco, M.A.F., 1998. Incrimination of Lutzomyia cruzi as a vector of American visceral leishmaniasis. Med. Vet. Entomol. 12, 315-317.

Sherlock, I.A., 1996. Ecological interactions of visceral leishmaniasis in the state of Bahia. Mem. Inst. Oswaldo Cruz 91, 671683.

Sherlock, I.A., Guitton, H., 1969. Observações sobre o calazar em Jacobina, Bahia. III. Alguns dados sobre o Phlebotomus longipalpis, o principal transmissor. Rev. Bras. Malariol. D. Trop. 21, 541-548.

Sherlock, I.A., Miranda, J.C., 1992. Is vector and reservoir control possible for visceral leishmaniasis. Rev. Soc. Bras. Med. Trop. 25,84 .

Silva, E.S., Gontijo, C.M.F., Pacheco, R.S., Fiuza, V.O.P., Brazil, R.P., 2001. Visceral leishmaniasis in the metropolitan region of Belo Horizonte, State of Minas Gerais. Braz. Mem. Inst. Oswaldo Cruz 96, 285-291.

Sudia, W.A., Chamberlain, R.W., 1962. Battery-operated light trap: an improved model. Mosq. News 22, 126-129.

Tesh, R.B., 1995. Control of zoonotic visceral leishmaniasis: is it time to change strategies? Am. J. Trop. Med. Hyg. 52, 287-292.

Travi, B.L., Montoya, J., Gallego, J., Jamarillo, C., Llano, R., Velez, I.D., 1996. Bionomics of Lutzomyia evansi (Diptera: Psychodidae) vector of visceral leishmaniasis in northern Colombia. J. Med. Entomol. 33, 278-285.

Travi, B.L., Velez, I.D., Brutus, L., Segura, I., Jamarillo, C., Montoya, J., 1990. Lutzomyia evansi, an alternate vector of Leishmania chagasi in a Colombian foci in the Pacific coast region. Trans. R. Soc. Trop. Med. Hyg. 84, 676-677.

Ward, R.D., Ribeiro, A.L., Ready, P.D., Murtaugh, A., 1983. Reproductive isolation between different forms of Lutzomyia longipalpis (Lutz \& Neiva) (Diptera: Psychodidae). Mem. Inst. Oswaldo Cruz 80, 145-148.

Young, D.G., Duncan, M.A., 1994. Guide to the identification and geographic distribution of Lutzomyia sand flies in Mexico, the West Indies, Central and South America (Diptera: Psychodidae). Mem. Am. Entomol. Inst. 54, 1-881. 